\title{
Proyecto de reconstrucción virtual de la ciudad griega de Empúries El Serapieion: un paseo por el santuario de Serapis
}

\author{
Tomàs Bases i Hernández \\ Infografista colaborador del Museu d'Arqueologia de \\ Catalunya -Empúries \\ Joaquim Monturiol i Sanés \\ Técnico de Difusión del Museu d'Arqueologia de \\ Catalunya -Empúries \\ importantes de la Península, que conserva los \\ restos de la ciudad griega de Emporion y de la \\ ciudad romana de Emporiae. Un conjunto \\ monumental, situado en un lugar idílico de la \\ Costa Brava, que cuenta con más de 2.500 \\ años de historia y que actualmente está prepa- \\ rando el dossier para presentar la candidatura a \\ la declaración de Patrimonio Mundial por la \\ UNESCO.
}

\section{Resumen}

En este artículo se da a conocer el proyecto de reconstrucción virtual de la ciudad griega de Emporion: la forma en que se materializó el proyecto, su planificación y realización, y el uso de las nuevas tecnologías con sus múltiples utilidades.

\section{Palabras clave}

Empúries / Plan Director / Reconstrucción virtual / 3D / Nuevas tecnologías.

\section{Introducción: Nace un proyecto}

Empúries forma parte del Museu d'Arqueologia de Catalunya y depende de la Generalitat de Catalunya. Es uno de los yacimientos más
El Museu d'Arqueologia de Catalunya - Empúries redactó, en 1998, el Plan Director 19982008 que recoge los proyectos de investigación, documentación, conservación y difusión previstos para ese período en el yacimiento arqueológico de Empúries. Precisamente, en el año 2008 se cumplirán 100 años de la recuperación institucional de Empúries y del inicio de las excavaciones, promovidas por Josep Puig i Cadafalch.

Precisamente, el tercer apartado del Plan Director comprendía, dentro de un paquete de intervenciones para la difusión y musealización, la creación de un cd rom con reconstrucciones virtuales de Empúries. Esta técnica permitiría, a los más de doscientos mil visitantes anuales con que cuenta el museo, tener una idea mucho más clara del funcionamiento de la ciudad en época antigua y a la vez ayudaría a

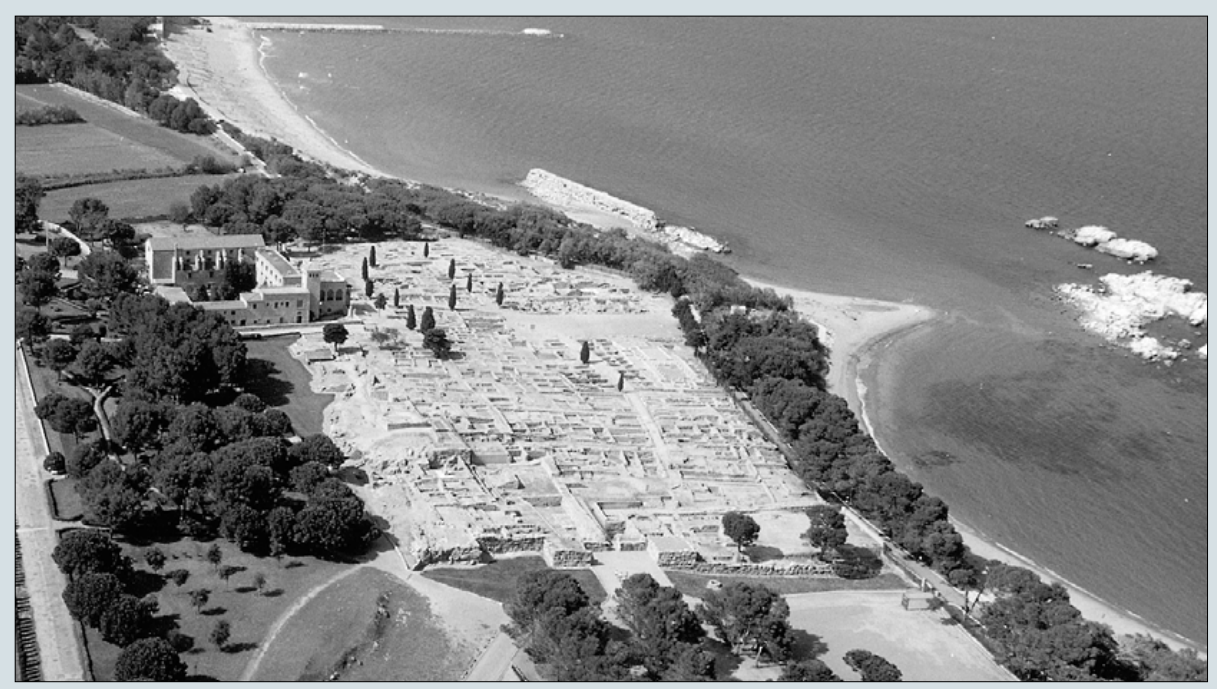




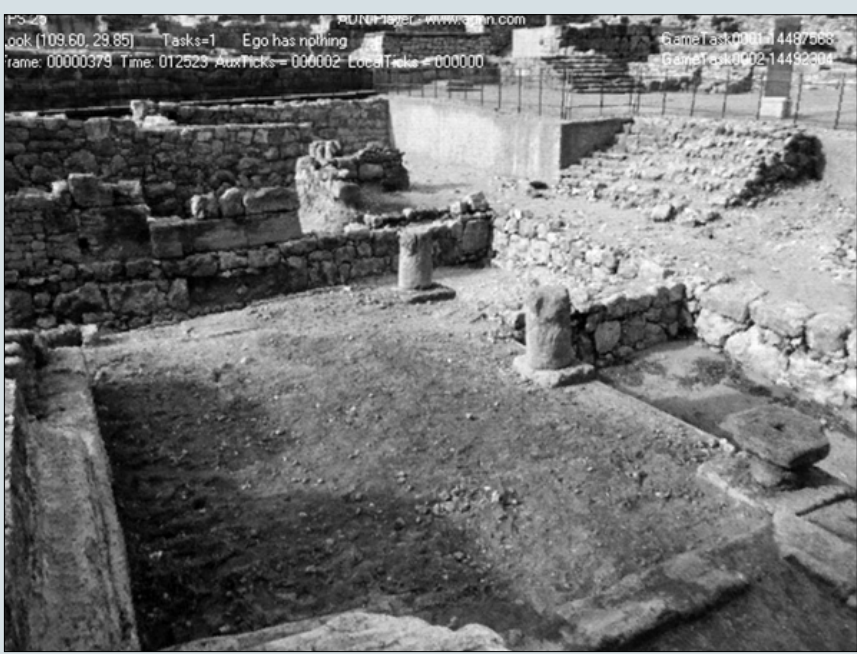

interpretar los restos arqueológicos conservados in situ.

La posibilidad de incluir propuestas de realidad virtual y restituciones de la antigua Emporiae haría mucho más comprensible a los visitantes, sus restos arqueológicos.

A principios de 2001 Tomàs Bases y Carlos Marín, profesionales de la imagen sintética (3D y animación), se plantean unir sus conocimientos en 3D e ilustración con su interés por la historia y la arqueología, y proponen al Museu d'Arqueologia de Catalunya - Empúries la posibilidad de desarrollar el proyecto de reconstrucción virtual.

El Museu d'Arqueologia de Catalunya Empúries apostó de inmediato por la enorme empresa de reconstruir virtualmente toda la ciudad griega de Empúries. El equipo técnico que redactó el proyecto está formado por Xavier Aquilué, director del MAC-Empúries; Pere Castanyer, Marta Santos y Joaquim Tremoleda, arqueólogos del MAC-Empúries; Joaquim Monturiol, técnico de difusión del MAC-Empúries; Tomàs Bases, Carles Marín i Ricard Serra, de la empresa de realidad virtual de Tomàs Bases.

El equipo técnico de Empúries se puso manos a la obra y proporcionó a los técnicos informáticos toda la documentación y el asesoramiento necesarios para la realización de una demo, así como el empeño en conseguir la financiación que permitiera la consecución del proyecto.

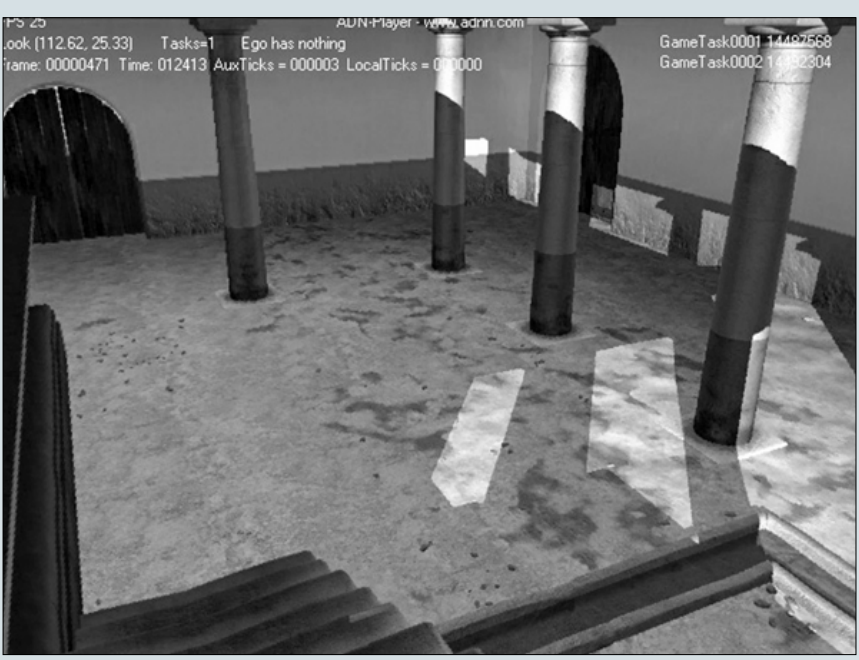

Entrada al templo y reconstrucción virtual (Fondo: Tomàs Bases/MAC-Empúries)
Precisamente este proyecto de restitución virtual de la griega Emporion se presentó públicamente en el II Congreso Internacional sobre musealización de yacimientos arqueológicos que tuvo lugar en Barcelona del 7 al 9 de octubre de 2002.

\section{Planificación del proyecto y documentación}

\section{La ciudad griega de Empúries}

Emporion fue una antigua ciudad fundada por griegos de origen foceo en el siglo VI a.C. Comprende la Palaiápolis (ciudad antigua), que fue el primer asentamiento, en la zona que actualmente ocupa el pueblo de Sant Martí d'Empúries. De la Palaiápolis tenemos poca información de su trama urbana en época antigua, puesto que se trata de un núcleo habitado de forma ininterrumpida desde la época del Bronce Final hasta la actualidad. De otra parte, comprende la Neápolis (término moderno para designar la ciudad de nueva planta que los griegos construyeron al otro lado del puerto de la Palaiápolis) que, bajo la dirección de Josep Puig i Cadafalch, se excavó desde 1908 hasta 1936. De esta parte, actualmente dentro del recinto del MAC-Empúries, tenemos mucha más información, puesto que se ha podido excavar en extensión, con lo cual hoy podemos recorrer sus calles, plazas, templos, mercados, casas, etc. Aún así, cabe señalar que los restos visibles actualmente en la Neápolis corresponden a la época helenística (s. |-II a.C.). Para poder ver las construcciones anteriores habría que desmantelar los restos de las construcciones helenísticas mencionados y excavar a más profundidad.

\section{La zona religiosa de la ciudad griega y el santuario de Serapis}

En la zona meridional de la Neápolis se encuentra el área destinada a las actividades religiosas de la ciudad. A cada lado de la puerta principal de entrada a la ciudad se ubica esta zona sagrada. En una terraza superior, se rendía culto a Asclepio, dios griego de la medicina. Precisamente, la famosa estatua de ese dios fue hallada en las excavaciones realizadas en esa zona en 1909. En una terraza inferior se rendía culto a Zeus Serapis, divinidad de origen egipcio relacionada también con la medicina y la curación de enfermedades.

En unas excavaciones del año 1909 se hallaron dos fragmentos de los pies de la escultura de Serapis, así como también una parte de las urpas del can cerbero que acompaña siempre al dios. Los restos de una inscripción bilingüe (griego y latín) sobre una pieza de mármol hallados también en esa zona corroboran que un personaje de origen alejandrino llamado Noumas, residente en Empúries en el siglo I a.C., hizo construir un templo dedicado a Zeus Serapis. Además, muy probablemente este santuario estuviera también consagrado a Isis. 

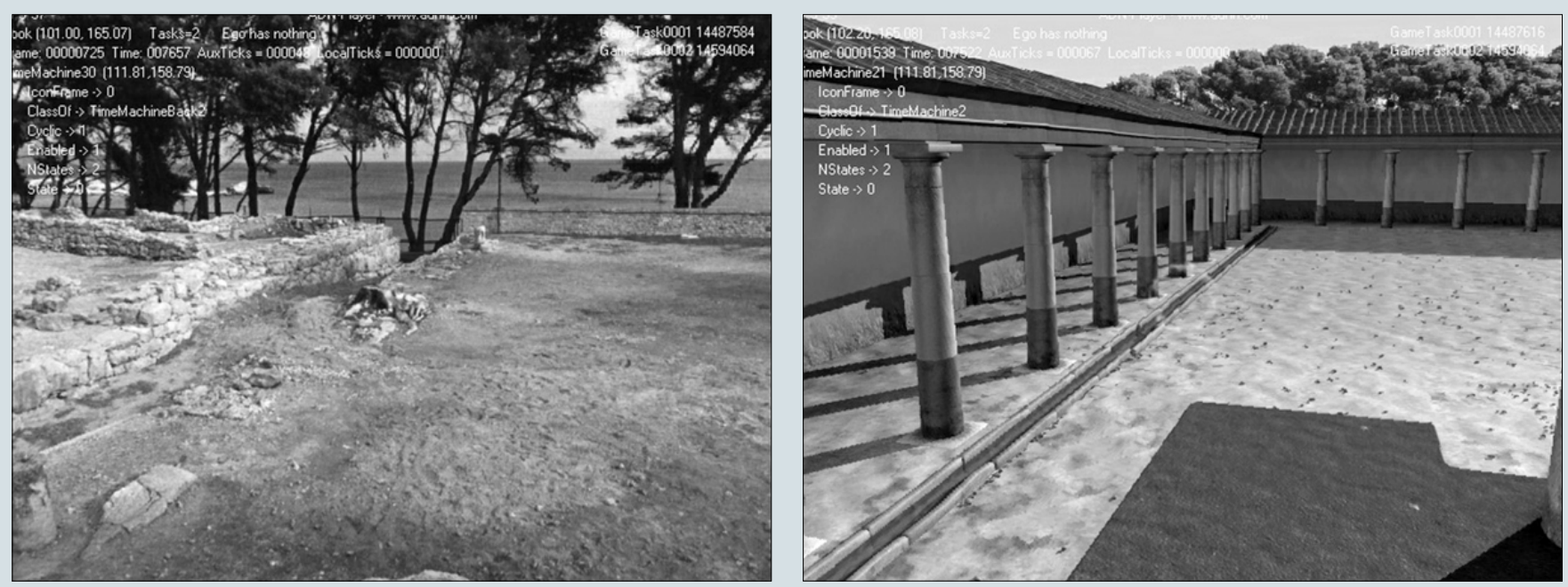

Vista de la plaza y reconstrucción virtual (Fondo: Tomàs Bases/MAC-Empúries)

Se trata de un templo tetrástilo sobre un podio, probablemente de estilo dórico, con escaleras laterales de acceso a la pronaos. El templo se encuentra en una plaza delimitada por un pórtico rectangular de columnas de orden dórico que lo rodea. La extensión aproximada del área delimitada por el pórtico es de $25 \mathrm{~m}$ de norte a sur $\times 50 \mathrm{~m}$ de este a oeste. Por la parte posterior del templo, detrás del porticado del lado oeste, cuenta con un ecclesiasterion, una gran estancia destinada a la reunión de fieles iniciados en los misterios isíacos. En el suelo, enfrente de todo el perímetro que describe el pórtico, se encuentra una canalización realizada en bloques de arenisca que recogía las aguas pluviales de los tejados y las evacuaba hacia el exterior del recinto urbano.

\section{La necesidad de una restitución virtual}

Uno de los objetivos principales del Museu d'Arqueologia de Catalunya - Empúries es conseguir que sus visitantes puedan interpretar los restos que visitan con las facilidades necesarias para poder entender el funcionamiento de los edificios o del conjunto de la ciudad. En el caso de Empúries, para los visitantes no iniciados, dicha interpretación requiere un esfuerzo de abstracción considerable.

Por ese motivo y también para dar un salto cualitativo hacia el futuro y situar el museo en la vanguardia de la innovación tecnológica aplicada a la interpretación arqueológica, se ha apostado por este proyecto de restitución virtual.
El sistema ha de permitir a los visitantes ver e interaccionar en una restitución virtual documentada científicamente, de los restos de la antigua Emporion. El proyecto contempla la restitución total de los edificios y las calles más destacados de la ciudad.

\section{Aplicaciones que puede tener el proyecto}

\section{Puntos de información sobre el terreno}

El objetivo principal sería poder instalar en diferentes zonas estratégicas del yacimiento de Empúries, puntos interactivos de información que ofreciesen al visitante la posibilidad de poder ver las restituciones de cada sector de la ciudad. Estos puntos informativos deben sustituir, a largo plazo, el actual sistema de información a través de paneles.

\section{Rom}

También está previsto editar una restitución reducida de toda la ciudad en formato de cd rom, o bien editar en diferentes cd la restitución completa de los principales edificios. Estos CD se pondrían a disposición del público que visita Empúries.

\section{Puntos de información fijos}

También se instalarían puntos de información fijos en el museo monográfico de Empúries, ayudando a dar una visión del conjunto del yacimiento antes de realizar la visita.

\section{Información en internet}

Parte de la información con las restituciones virtuales se podría instalar en la página web del MAC-Empúries.

\section{Navegación y programación}

El elemento clave es el sistema de navegación de entornos esféricos prerrenderizados "ADN software", desarrollado por la empresa Zenit. Este software de navegación permitió apostar por una calidad gráfica muy realista, que sumada a la interactividad y a la utilización paralela de fotografías panorámicas, completan una propuesta que acaba de tomar forma de la mano del Museu d'Arqueologia de Catalunya-Empúries.

ADN software permite al espectador pasearse a través de un escenario virtual, con la ventaja -respecto a otros simuladores virtuales- de permitir una excelente calidad gráfica, pues se trata de imágenes que no se generan a tiempo real dentro del ordenador del usuario sino que ya están generadas previamente por los ordenadores del equipo de producción. La navegación se realiza a través de entornos esféricos, lo que permite una completa visión del escenario. Podemos pasar de la escena donde aparece la reproducción virtual a la misma escena pero con una fotografía panorámica de los restos arqueológicos ubicados en ese mismo lugar. El software nos permite asimismo implementar hipervínculos, reproducir video y audio y ejecutar aplicaciones externas. Este Software 
funciona en entorno de Windows y dispone de plug-in's para Macromedia Director, Internet Explorer y Netscape Navigator.

\section{Realización gráfica}

\section{Modelado en 3 dimensiones}

El primer paso consistió en levantar el templo de Serapis y todo el pórtico que lo rodeaba a partir de los datos científicos obtenidos en la investigación arqueológica realizada. Los planos, alzados y estructuras se han realizado sobre la base de las indicaciones del equipo técnico del Museu d'Arqueologia de Catalunya - Empúries que realiza el seguimiento del proyecto.

La exactitud en las escalas fue elemento fundamental, no sólo por el interés del proyecto para seguir con fidelidad lo que fue la realidad histó- rica, sino también por el reto técnico que supuso la relación existente en la demo de imagen virtual con fotografías panorámicas. También se procuró realizar un trabajo poligonal muy limpio, en el que no hubiesen más polígonos de los necesarios. Un exceso de geometría podría crear serios problemas a la hora de generar las imágenes de la ciudad entera.

Una vez modelada la geometría se pasa a aplicar las texturas. Para ello se intenta partir siempre de la máxima proximidad de la cámara con la que se navegará a las superficies que se encuentran a lo largo de los recorridos. A dicha distancia las texturas debían ser claras y carentes de pixelación; pero al mismo tiempo, al alejarnos, se tenían que evitar los mosaicos provocados por la repetición del patrón (textura).

En la iluminación de la demo se descartó la utilización de un sistema de iluminación con radiosidad, aunque sería deseable este sistema para la realización del conjunto del proyecto. Éste sistema permite al ordenador calcular, a partir de un solo foco de luz, la iluminación indirecta que las superficies iluminadas generan sobre las no iluminadas, simulando de forma muy realista la iluminación de una escena. Sin embargo, la viabilidad de la realización de esta demo nos impidió utilizar esta tecnología, que hubiese supuesto unos tiempos de render (tiempo que se tarda en generar las imágenes sintéticas) superiores a los disponibles. Se optó pues por una iluminación tradicional, en la que se parte de un foco principal al que se van sumando luces que iluminen zonas puntuales.

También se optimizó mucho la utilización de las sombras Raytrace, las cuales ofrecen unos excelentes resultados. Generar este tipo de sombra es uno de los motivos que más aumentaba el tiempo de render, por lo que sólo se aplicó a los objetos imprescindibles.
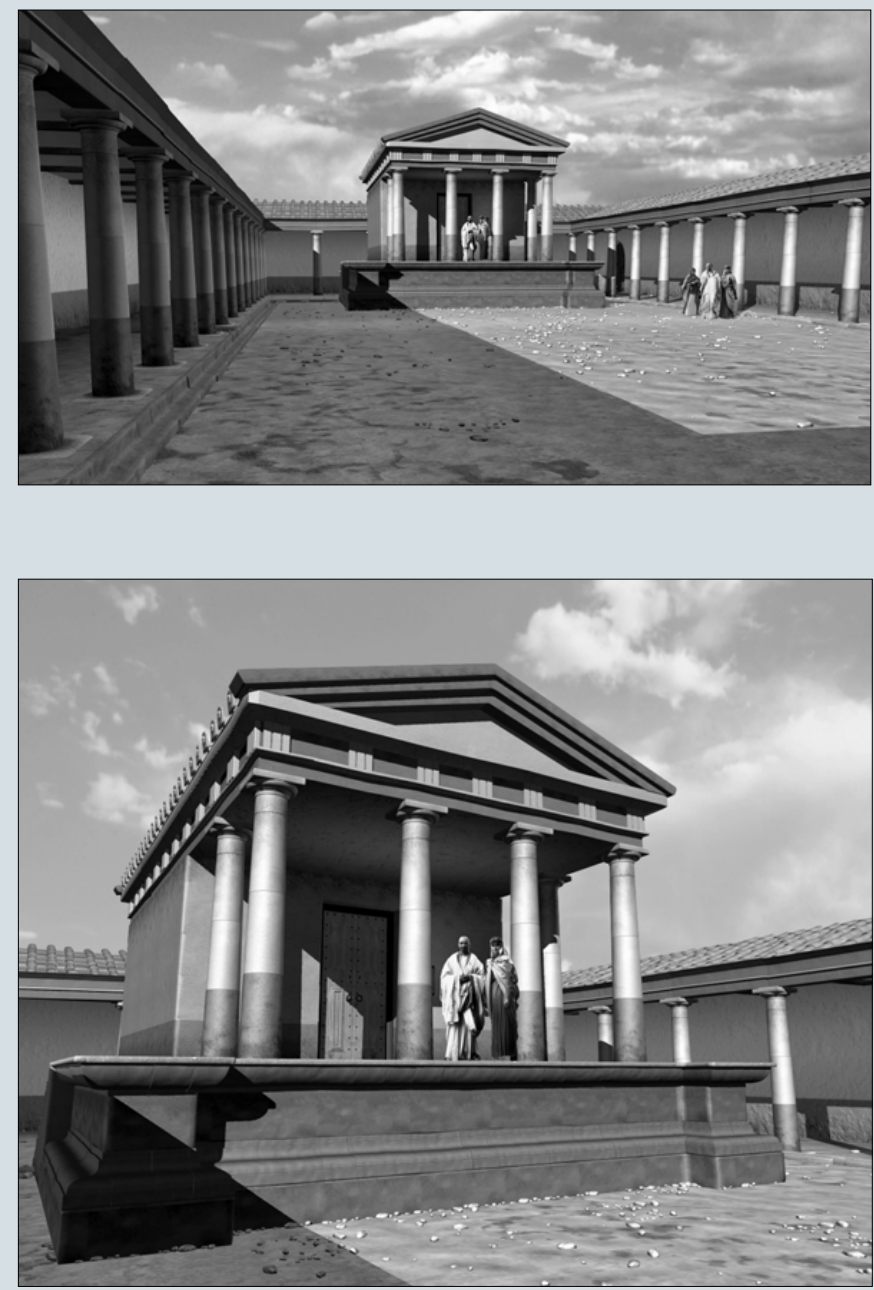

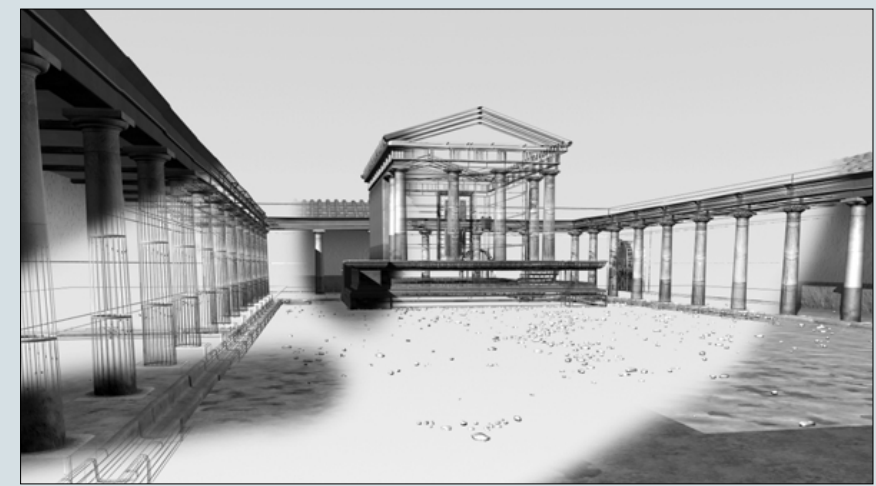

Reconstrucción de la plaza y el templo (Fondo: Tomàs Bases/MAC-Empúries)

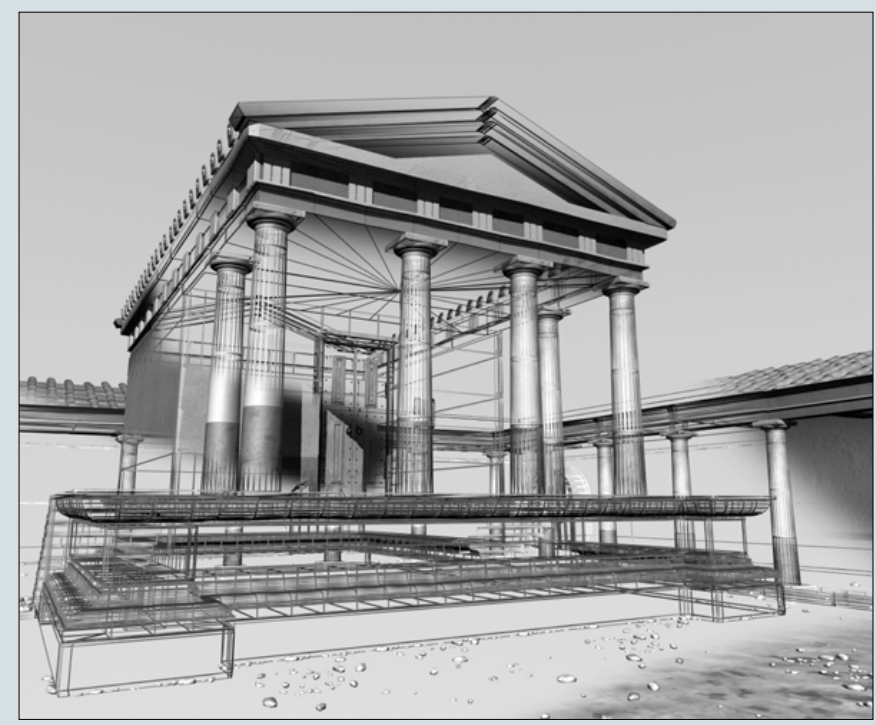

Reconstrucción de la fachada del templo (Fondo: Tomàs Bases/MAC-Empúries) 
Otro elemento importante fue el modelado de la estatua de Serapis. De esta estatua sólo nos quedan los pies de mármol del Dios, así como la garra izquierda delantera del can Cerbero. A partir de estos elementos y basándonos en otras estatuas dedicadas a este Dios se inicia el trabajo de modelado. Se utilizan para ello "splines editables", es decir, una serie de líneas tridimensionales que van perfilando la forma de la estatua. Este método de modelado permitió un gran detallismo, aplicándose también en la reproducción de otros elementos escultóricos, como los pebeteros o los soportes para las velas del interior del templo.

\section{Animaciones}

Sin duda la animación se convierte en un magnífico medio de comunicación, permitiéndonos plasmar conceptos e ideas complejas de forma amena y sencilla.

El sofware de navegación nos permite lanzar animaciones en formato de video mpeg 2 , como si fuesen proyecciones que se visualizan en una parte de la pantalla, o hacer que en los propios nodos del recorrido virtual se activen, de forma interactiva, animaciones a pantalla completa ofreciendo una mayor sensación de "inmersión" al espectador.

En la demo se proyecta una animación explicativa de los cánones arquitectónicos griegos, en la que, poniendo como ejemplo el mismo templo de Serapis, se explica de forma muy visual cómo se aplicaban dichos cánones. También se lanzan, de forma interactiva (es decir, sólo si el espectador lo decide) animaciones explicativas de la estatua del Dios Serapis y de la placa con inscripción ubicada a la entrada del templo. En este último caso se juega con la comparativa entre la placa tal como se considera que fue y los restos que actualmente se conservan de ella.

\section{El horizonte de una nueva tecnología}

Sinceramente pensamos que la informática y más concretamente la realidad virtual ayudarán, mucho más de lo que lo hacen en la actualidad, a la comprensión y estudio de la Historia. La recreación virtual puede ser un magníico trabajo de campo sin el problema y el dilema que supone actuar directamente sobre las ruinas.

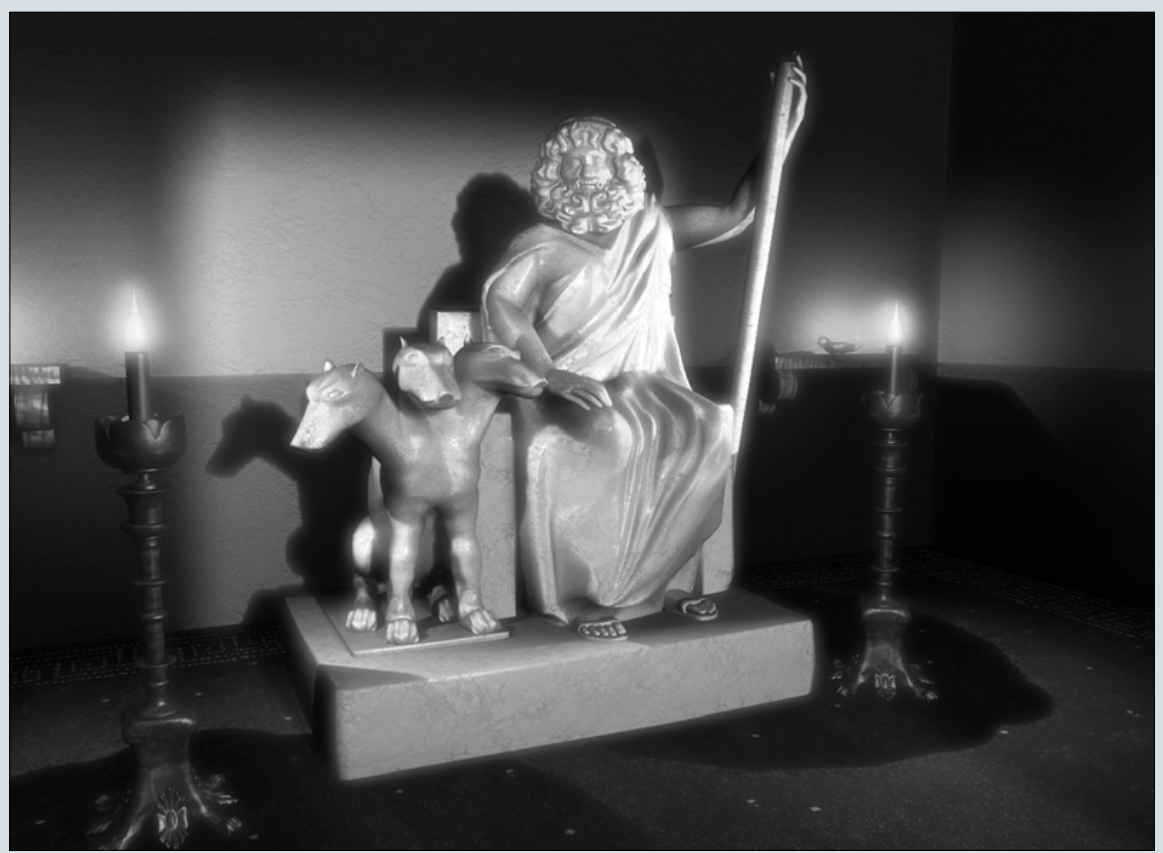

La excavación y el estudio de los restos encontrados se completarán con la reconstrucción virtual de todo el yacimiento. Desde el primer momento la realidad virtual podrá ser de ayuda en el estudio ya que consideramos fundamental la participación del arqueólogo en esta fase de trabajo. Paredes, soportes, vigas, tejas, decoración, colores, texturas, etc., al igual que en una construcción real, se deben tener en cuenta en el momento de la reconstrucción por ordenador. Una vez finalizada la reconstrucción informática el arqueólogo tendrá una visión acabada y completa de lo que debió ser el yacimiento en las diferentes épocas de uso. El usuario podrá pasearse entre los edificios, entrar en ellos e incluso hacer uso de los elementos que existiesen en la época: baños, templos, factorías, mercados... y sacar sus propias conclusiones.

A nivel educativo esta tecnología une los contenidos culturales a una forma agradable y lúdica de entender conceptos. Sin duda es un acercamiento de la cultura a una sociedad que, cada vez más, entiende el concepto a través de la imagen.

\section{Bibliografía}

X. Aquilué, P. Castanyer, M. Santos, J. Tremoleda, Empúries, Guies del Museu d'Arqueologia de Catalunya, Tarragona, 1999.

$X$. Aquilué, "El conjunto arqueológico de Empúries (I'Escala, Girona) y su relación con su entorno territorial", en Actas de los XI cursos monográficos sobre el patrimonio histórico, Reinosa, 2000.

X. Aquilué, Pla Director del Museu d'Arqueologia de Catalunya-Empúries. Un projecte pel Primer Centenari de la recuperació d'Empúries (1908-2008). Vol. I: Proposta dels programes de recerca, documentació, conservació i difusió d'Empúries, Generalitat de Catalunya, 1998.

R. Mar, J. Ruíz de Arbulo, Ampurias romana. Historia, arquitectura y arqueología, Sabadell, 1993.

E. Sanmartí, P. Castanyer, J. Tremoleda, "Emporion, un ejemplo de monumentalización precoz en la Hispania republicana. Los santuarios helenísticos de su sector meridional", Stadtbild und Ideologie (Madrid 1987), Munic, 1990, pp.117-143.

E. Sanmartí, "Identificació iconogràfica i possible atribució d'unes restes escultòriques trobades a la Neàpolis emporitana al simulacrum del Serapis d'Emporion", Miscel/lània Arqueológica a Josep M. Recasens, Tarragona, 1992, pp. | 45-154. 